\title{
Joining of SiC Ceramics by the Flash-Bonding Technique
}

\author{
Takuro Yoshitake, Yoshio Ohta, Mikito Kitayama \\ Department of Life Environment and Applied Chemistry, Fukuoka Institute of Technology, Fukuoka, Japan \\ Email: kitayama@fit.ac.jp
}

How to cite this paper: Yoshitake, T., Ohta, Y. and Kitayama, M. (2020) Joining of $\mathrm{SiC}$ Ceramics by the Flash-Bonding Technique. Journal of Materials Science and Chemical Engineering, 8, 52-65.

https://doi.org/10.4236/msce.2020.83004

Received: February 12, 2020

Accepted: March 10, 2020

Published: March 13, 2020

Copyright (c) 2020 by author(s) and Scientific Research Publishing Inc. This work is licensed under the Creative Commons Attribution International License (CC BY 4.0).

http://creativecommons.org/licenses/by/4.0/

\begin{abstract}
Because Silicon carbide $(\mathrm{SiC})$ ceramics have various excellent properties, the demand for larger and complicated shapes has been increasing. This paper introduces an innovative method that would not require a large furnace, and further, would minimize the production cost and the thermal history, namely the "flash-bonding" technique. The borosilicate glass with low thermal expansion coefficient, Pyrex glass, was selected as the brazing material. In this work, as-is or surface-oxidized SiC plates were joined using Pyrex glass as brazing material, and the reaction and wetting of Pyrex glass on as-is or surface-oxidized $\mathrm{SiC}$ plate were investigated. It was found that the protective film of the surface-oxidized $\mathrm{SiC}$ lowered the oxygen partial pressure, and hence, generated many pores in the interface.
\end{abstract}

\section{Keywords}

Silicon Carbide, Joining, Flash-Bonding, Borosilicate Glass

\section{Introduction}

With the development of aerospace, nuclear power, semiconductor industry, and so on, a demand for high performance materials that can bear under harsh conditions has been rising [1] [2]. Silicon carbide ( $\mathrm{SiC}$ ) has been applied not only to industrial components such as high temperature parts, heat exchangers, and wear resistant parts, but also to power device, manufacturing equipment parts of semiconductor and mirror substrates for space optics [3] [4] [5], because of its superior properties including high thermal and chemical stability, wear resistance, high thermal conductivity, low thermal expansion and low bulk density [6] [7] [8] [9]. However, $\mathrm{SiC}$ has been known to have same drawbacks; the solid-state sintering of $\mathrm{SiC}$ ceramics requires extremely high temperature 
under a vacuum or Ar condition due to its low self-diffusion coefficient, and has poor machining property due to its high hardness and brittle nature because of its strong covalent bonding ( $\mathrm{C}-\mathrm{Si}$ ), which have prevented $\mathrm{SiC}$ from widening its application for big and complicated structural parts [10] [11]. One solution is the additive manufacturing technologies [9] [12] [13], and the other would be the bonding technologies that are divided into three major categories; direct bonding, bonding with interlayer materials, and mechanical bonding [14]. For example, Mo foil was sandwiched between two SiC plates and hot-pressed at $1500^{\circ} \mathrm{C}$ in a vacuum to yield joined parts with bending strength of $263 \mathrm{MPa}$ [15], and joined parts by the laser heating technique using a $\mathrm{SiO}_{2}-\mathrm{Al}_{2} \mathrm{O}_{3}-\mathrm{Y}_{2} \mathrm{O}_{3}$-based oxide ceramic as an interlayer material enabled average joining strength as high as $319 \mathrm{MPa}$ [16]. In the former method, an electric furnace was used for heating the joint, however, when manufacturing a large joined body, its size would be restricted by the size of the furnace used. Further, enormous energy would be required when using a large furnace and the thermal history might deteriorate the ceramic parts seriously. In the latter method, the local heating by the laser irradiation would excessively heat the joint to deteriorate the mechanical properties of a joined body, which would severely require the thermal property matching of the ceramic base and the interlayer material [16].

This paper introduces an innovative method for bonding $\mathrm{SiC}$ ceramics that would realize the "furnace-free" and "instantaneous" bonding, herein called as the "flash-bonding technique". As shown in Figure 1, SiC parts, brazing and heating materials are stacked each other, and the joule heat from the heating material by applying high current could instantaneously melt the brazing materials to wet and bond the two surfaces of SiC ceramic parts. Apparently, this technique would not require a large furnace, and further, would minimize the production cost and the thermal history. In this work, the borosilicate glass with low thermal expansion coefficient, Pyrex glass, was selected as the brazing material. The purpose of this work is to investigate the reactivity and wettability of Pyrex glass with SiC ceramics.

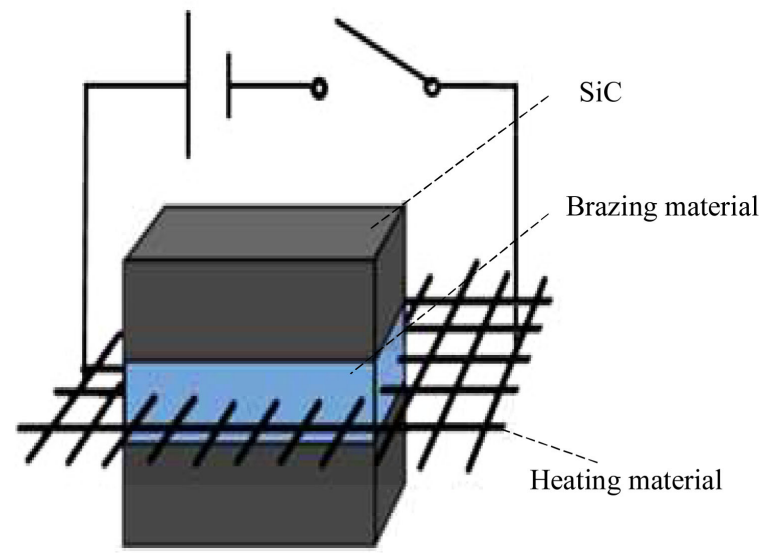

Figure 1. Schematic diagram of the "flash-bonding" technique: SiC and brazing materials were stacked above and below the heating material. 


\section{Experimental}

\subsection{Materials}

Reaction sintered $\mathrm{SiC}$ (RS-SiC) was used as the joining base material. Its thermal properties depend on the melting point of residual $\mathrm{Si}$ about $1410^{\circ} \mathrm{C}$ and the coefficient of thermal expansion (CTE) of $4.4 \times 10^{-6} / \mathrm{K}$. Brazing material has some necessary conditions such as electrical insulation, phase compatibility with $\mathrm{SiC}$, good wettability on $\mathrm{SiC}$, melting temperature lower than the melting point of $\mathrm{Si}\left(1414^{\circ} \mathrm{C}\right)$ and $\mathrm{CTE}$ value close to $\mathrm{SiC}$. In this work, low thermal expansion borosilicate glass, Pyrex glass, was employed. The CTE of the heating material also should be similar to $\mathrm{SiC}$, and must be a refractory metal with high oxidation resistance and electrical conductivity. Thus, Tungsten (W; melting point $=$ $3387^{\circ} \mathrm{C}, \mathrm{CTE}=4.3 \times 10^{-6} / \mathrm{K}$ ) was selected in this work.

\subsection{Preparation of RS-SiC Specimen}

The reaction sintering (RS) technique was used for fabricating bulk SiC ceramics, since it had several advantages such as low sintering temperature, near netshape forming and nearly full density by the infiltration of the liquid $\mathrm{Si}$, although the residual Si might affect the flexural strength of $\mathrm{SiC}$ [17]. Commercial $\mathrm{SiC}$ powder (GC100 grade, Maruto Ltd., Japan) was mixed with the resol-type phenolic resin (HP3000A, Asahi-Yukizai Kogyo Ltd., Japan) and curing agent (HA305k Asahi-Yukizai Kogyo Ltd., Japan), was cured at $55^{\circ} \mathrm{C}$ for $12 \mathrm{hrs}$ to give a resin composite with the $\mathrm{SiC}$ volume fraction about $45 \%$, which was subsequently dewaxed in a flowing $\mathrm{N}_{2}$ atmosphere to prepare a green body composed of $\mathrm{SiC}$ and carbon using a heating program shown in Figure 2. As shown in Figure 3, a dewaxed green body was put on to the bottom of a graphite susceptor, then surrounded by the Si powder (code No. 198-054555455, Wako Pure Chemical Crop., Japan) of which amount was equal to the 1.1 times its pore volume, and was heat treated in vacuum at $1500^{\circ} \mathrm{C}$ for $1 \mathrm{hr}$ for Si infiltration. The RS-SiC sintered bodies were cut into pieces $(10 \times 10 \times 2 \mathrm{~mm})$ using a high-speed diamond blade (CD-SD14OB, Maruto Ltd., Japan).

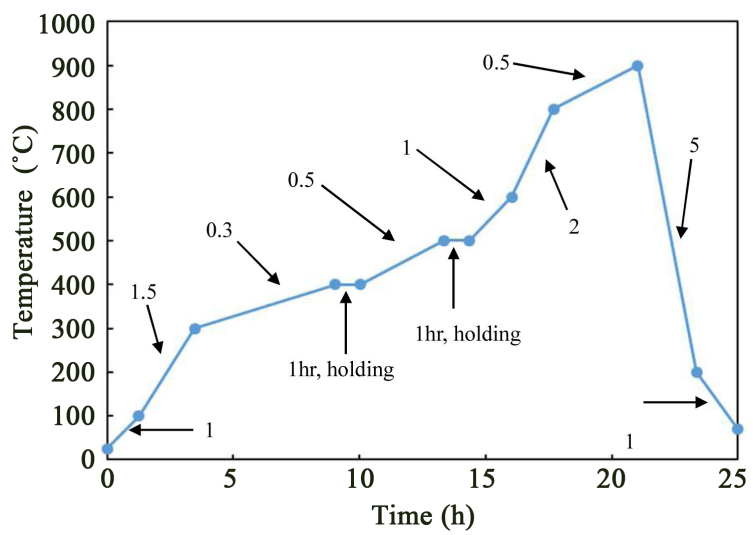

Figure 2. Heating program for dewaxing; the numbers in the figure indicate the heating rate $\left({ }^{\circ} \mathrm{C} / \mathrm{min}\right)$. 


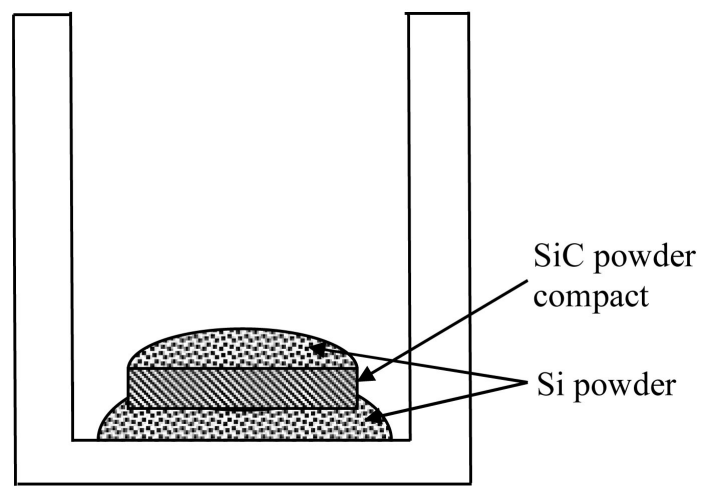

Figure 3. SiC powder compact embedded in Si powder in a graphite susceptor.

In this work, the brazing material, Pyrex glass, may react with $\mathrm{SiC}$ during bonding to generate the gaseous phases such as $\mathrm{CO}$ and/or SiO. Therefore, the formation of $\mathrm{SiO}_{2}$ protective film on the surface of $\mathrm{RS}-\mathrm{SiC}$ ceramics was attempted, since it could protect the $\mathrm{SiC}$ surface from the exposure of residual oxygen gas, and delay the oxygen diffusion from the Pyrex glass at high temperatures [18]. As-is $\mathrm{SiC}$ specimens were heat-treated at $1200^{\circ} \mathrm{C}$ for $3 \mathrm{hrs}$ in the air using a ceramic tube furnace (DSPSH-39, Siliconit Co. Ltd., Japan) to make surface-oxidized SiC specimens. Figure 4(a) and Figure 4(b) show SEM micrographs of as-is and surface oxidized $\mathrm{SiC}$ surfaces, respectively, and the latter clearly shows the existence of $\mathrm{SiO}_{2}$ protective film on the $\mathrm{SiC}$ surface.

\subsection{Preparation of the Brazing Materials}

The composition of Pyrex glass was slightly modified to have a softening point around $900^{\circ} \mathrm{C}$ and $\mathrm{CTE}$ value around $4.3 \times 10^{-6} / \mathrm{K} ; 64.0 \mathrm{SiO}_{2}-30.4 \mathrm{~B}_{2} \mathrm{O}_{3}-2.8 \mathrm{Na}_{2} \mathrm{O}-$ $1.8 \mathrm{Al}_{2} \mathrm{O}_{3}-0.9 \mathrm{~K}_{2} \mathrm{O}$ (mol\%) [19]. Reagent grade $\mathrm{SiO}_{2}, \mathrm{H}_{3} \mathrm{BO}_{3}, \mathrm{Na}_{2} \mathrm{CO}_{3}, \mathrm{Al}_{2} \mathrm{O}_{3}$ and $\mathrm{K}_{2} \mathrm{CO}_{3}$ powders were weighed to make the total amount of $20 \mathrm{~g}$ mixture, which was ground using a mortar and pestle for $1 \mathrm{hr}$. The mixed powder was transferred to a platinum crucible, and was melted at $1500^{\circ} \mathrm{C}$ for $1 \mathrm{hr}$ using a ceramic tube furnace (DSPSH-39, Siliconit Ltd., Japan) in air.

\subsection{Wetting Experiment of Pyrex Glass on SiC Specimen}

A bulk of Pyrex glass was crushed into pieces with about a few $\mathrm{mm}$ size, and was placed on an as-is or surface-oxidized SiC plate. This assembly was placed in a ceramic tube furnace, subsequently was evacuated with an oil-sealed rotary vacuum pump, and was heat-treated to a target temperature and held for $30 \mathrm{~min}$. The target temperatures are $900^{\circ} \mathrm{C}$ to $1200^{\circ} \mathrm{C}$ at $50^{\circ} \mathrm{C}$ intervals, consequently, 12 samples were prepared. Each sample was cross-sectioned using a high-speed diamond blade (CD-SD14OB, Maruto Ltd.) to observe the specimen using an optical microscope (VH-5000; KEYENCE Inc., Japan).

\subsection{Joining Experiment}

Pyrex glass was pulverized with a WC vibrational mill (P-0, FRITSCH Ltd., 

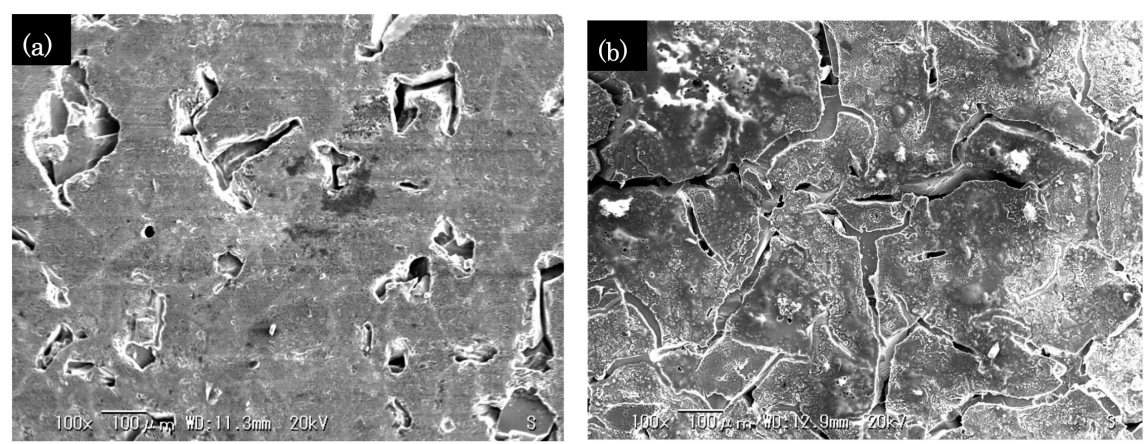

Figure 4. SEM micrographs of $\mathrm{SiC}$ surfaces; (a) as-is $\mathrm{SiC}$ and (b) surface-oxidized SiC.

Japan). The Pyrex glass powder was sieved using a 140 mesh' (106 $\mu \mathrm{m})$ sieve and was mixed with methanol to form paste. About $0.5 \mathrm{~mm}$ thickness of the paste was applied to each one side of two SiC plates, and W-mesh (30 mesh', wire diameter $=0.1 \mathrm{~mm}$; Nilaco Ltd., Japan) was sandwiched between them. This assembly was set in a vacuum deposition apparatus (HUS-5GB; Hitachi, Ltd., Japan) as shown in Figure 5. The vacuum chamber was evacuated using an oilsealed rotary vacuum pump, and then, $40 \mathrm{~A}$ of electrical current was supplied for $90 \mathrm{sec}$ from the two electrodes that are connected to the ends of a W-mesh. After cooling, the inside of the vacuum chamber was returned to the atmospheric pressure. A joined specimen was cross-sectioned using a high-speed diamond blade (Maruto Ltd., CD-SD14OB) to observe the SiC-Pyrex glass interface using an optical microscope (VH-5000; KEYENCE Inc., Japan). The SiC-Pyrex glass interface was polished using the cross-section polisher (IB-19500CP, JEOL Ltd., Japan) to observe the microstructure and chemical composition of the interface using the field-emission scanning electron microscope (FE-SEM) with an energy-dispersive X-ray (EDX) spectrometry (JSM-7401F and JED-2300, JEOL Ltd., Japan).

\section{Results and Discussion}

\subsection{Wettability and Reactivity of Pyrex Glass}

Figure 6(a) and Figure 6(b) show the cross-sections of specimens after wetting experiments at 900 (softening point of Pyrex glass), $950^{\circ} \mathrm{C}, 1000^{\circ} \mathrm{C}$ and $1050^{\circ} \mathrm{C}$ on (a) as-is and (b) surface oxidized $\mathrm{SiC}$, respectively. All wetting angles of Pyrex glass sessile drops on the as-is $\mathrm{SiC}$ plate were greater than 90 degrees (non-wetting) and showed little change with raising temperature, while the wetting angles on the surface-oxidized $\mathrm{SiC}$ plates gradually decreased with raising temperature. Figure 7(a) and Figure 7(b) show the cross-sections of specimens after wetting experiments at $1100^{\circ} \mathrm{C}, 1150^{\circ} \mathrm{C}$ and $1200^{\circ} \mathrm{C}$ on (a) as-is and (b) surface oxidized $\mathrm{SiC}$, respectively. The wetting angles of Pyrex glass sessile drops on the surface-oxidized $\mathrm{SiC}$ plates became less than 90 degrees (wetting) at $1100^{\circ} \mathrm{C}$, although a Pyrex glass sessile drop on the as-is $\mathrm{SiC}$ was observed to be deformed at the same temperature. At more than $1100^{\circ} \mathrm{C}$, all Pyrex glass sessile drops were 


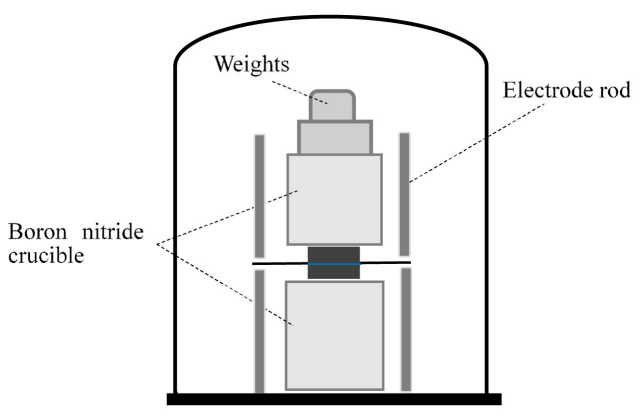

Figure 5. Schematics of setting for the flash-bonding; both ends of W mesh are connected to two electrodes, and the whole assembly is covered by a vacuum chamber.

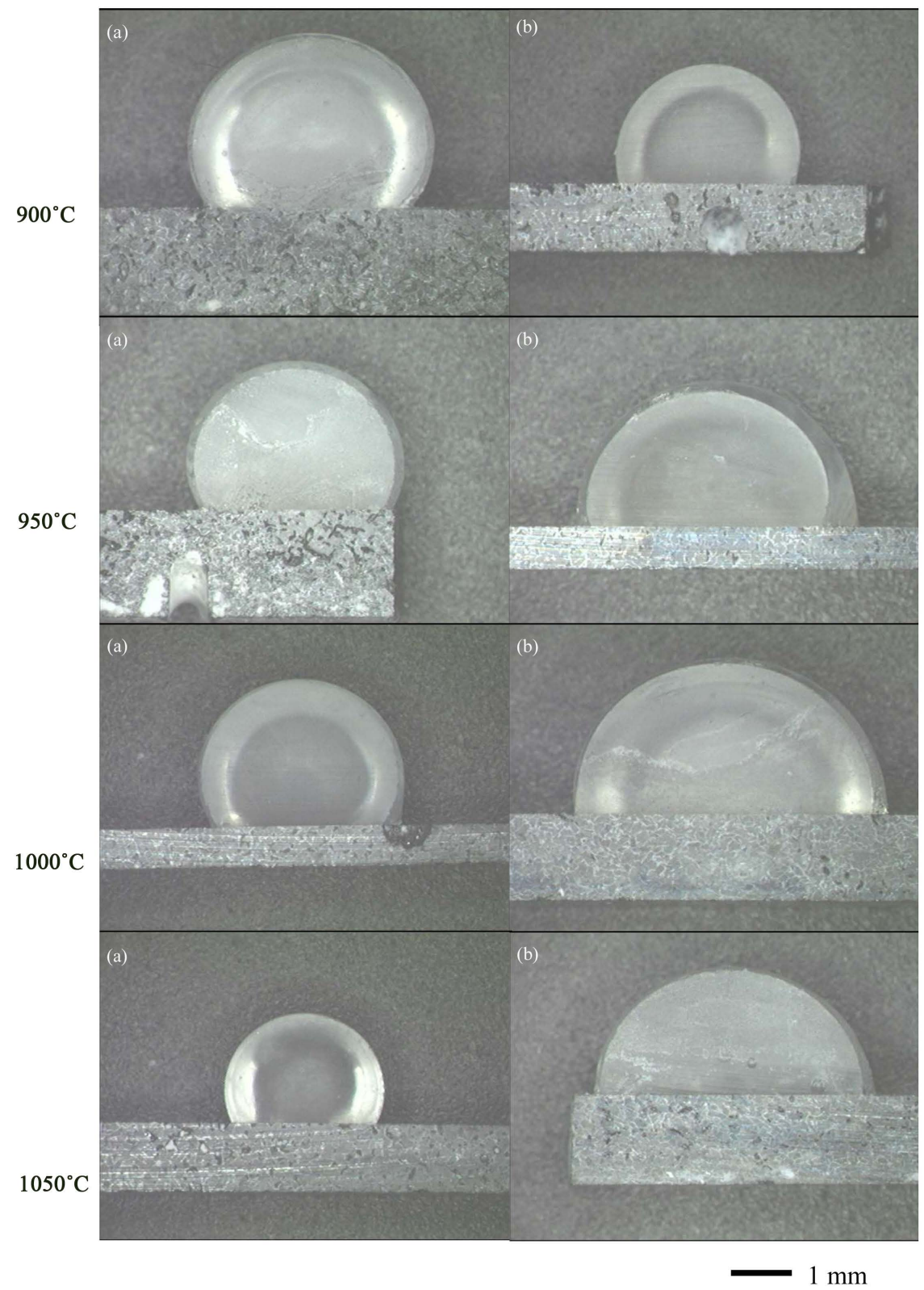

Figure 6. Cross-sections of Pyrex glass sessile drops at $900^{\circ} \mathrm{C}, 950^{\circ} \mathrm{C}, 1000^{\circ} \mathrm{C}$ and $1050^{\circ} \mathrm{C}$ on (a) as-is and (b) surface-oxidized SiC plate. 


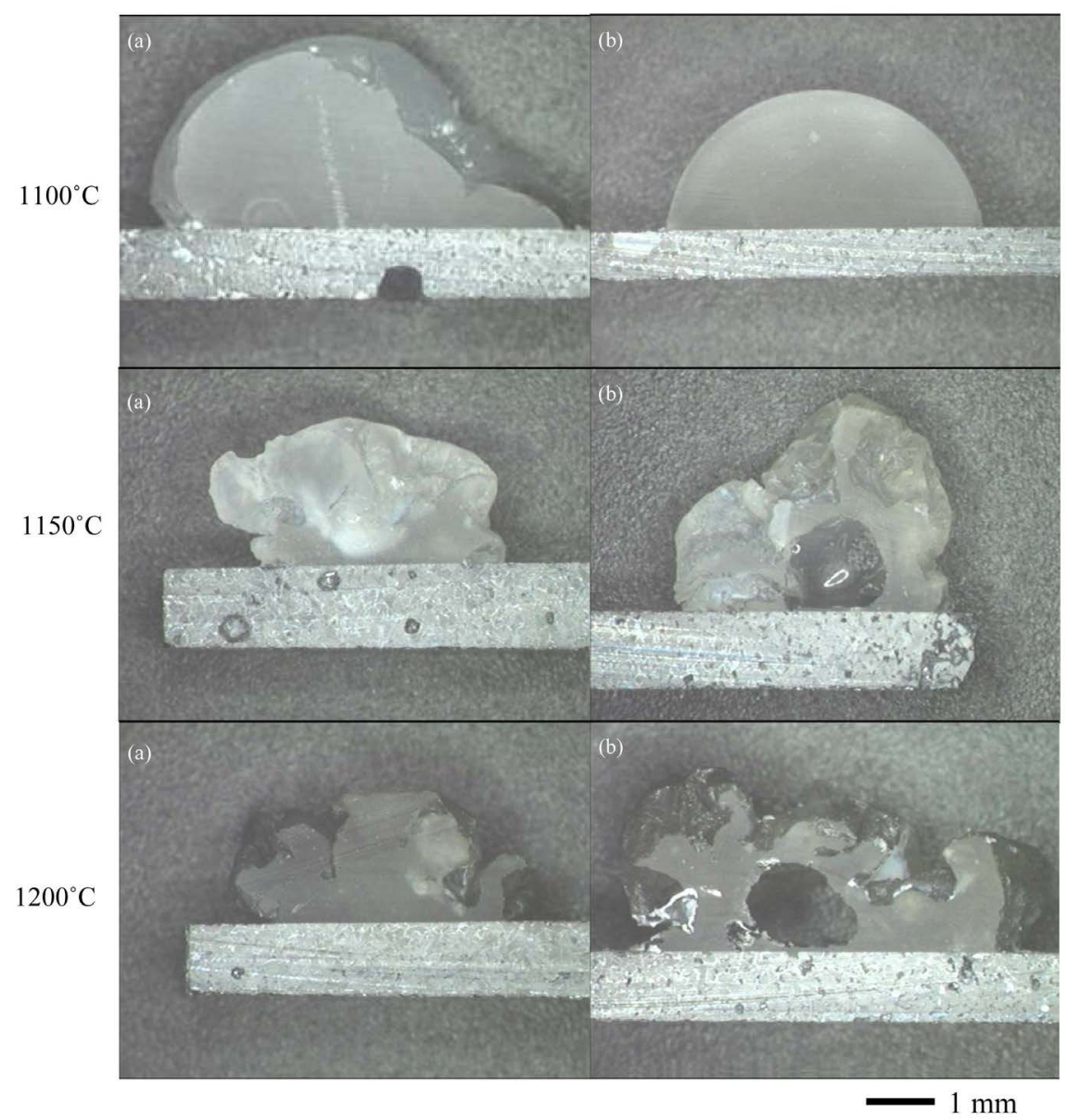

Figure 7. Cross-sections of Pyrex glass sessile drops at $1100^{\circ} \mathrm{C}, 1150^{\circ} \mathrm{C}$ and $1200^{\circ} \mathrm{C}$ on (a) as-is and (b) surface-oxidized $\mathrm{SiC}$ plate.

observed to be severely deformed, and further, large pores were observed only on the surface-oxidized SiC. The severe deformation and pore generation in the sessile drops would be due to the gas evolution that caused by the reaction between RS-SiC and Pyrex glass and/or residual oxygen gas, which will be discussed later in detail. The current results suggest that the desirable condition for joining would be at $1100^{\circ} \mathrm{C}$ using the surface-oxidized $\mathrm{SiC}$.

\subsection{Optical Observation of the $\mathrm{SiC} / J$ oining Layer}

After cutting using a high-speed diamond blade, all joined specimens were survived without debonding, which clearly indicates that all the joined bodies made by the Flash-bonding technique possessed certain levels of strength high enough for machining. Figure 8(a) and Figure 8(b) show the optical micrographs of the cross sections of the joining bodies made of as-is and surface-oxidized $\mathrm{SiC}$ plates, respectively. It was observed that the $\mathrm{SiC} /$ joining layer made of the as-is $\mathrm{SiC}$ plates had almost no pores, and its color was blackened, and in contrast, the $\mathrm{SiC} /$ joining layer made of the surface-oxidized $\mathrm{SiC}$ had a large amount of pores, and its color remained colorless and transparent. 


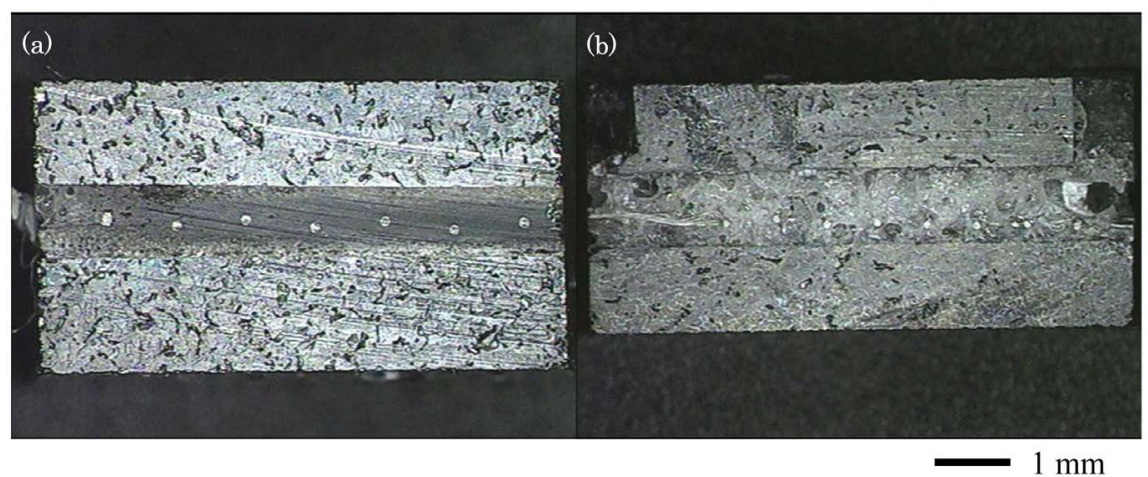

Figure 8. Cross-section optical micrographs of joined assembly; (a) using the as-is $\mathrm{SiC}$ plate and (b) using the surface-oxidized $\mathrm{SiC}$ plate.

\subsection{FE-SEM Observation and EDX Analysis of the SiC/Joining Layer}

Figures 9(a)-(d) show the microstructures of SiC/joining layers made of the surface-oxidized SiC plate observed by using the FE-SEM. As observed in the optical microscope, many pores are visible in the whole interlayer (a). In the vicinity of the SiC interface shown in Figure 9(b), many petal-like precipitates are observed in the interlayer, and some bright spots exist at the $\mathrm{SiC}$ interface. As shown in Figure 9(c), an apparent layer structure is observed between the interlayer and $\mathrm{SiC}$, which would be the $\mathrm{SiO}_{2}$ protective film of the surface-oxidized $\mathrm{SiC}$. At the W/interlayer interface shown in Figure 9(d), the interfacial debonding and some cracks are clearly observed. Figure 10(a) and Figure 10(b) demonstrate the EDX elemental analysis results at points 1 and 2, respectively, in Figure 14(b). $\mathrm{C}$ and $\mathrm{O}$ signals at point 1 are relatively stronger than those at point 2 , and $\mathrm{Si}$ signals at point 2 are much stronger than at point 1 . Figure 11 shows the EDX line analysis result along the line shown in Figure 9 (c). It is observed that the $\mathrm{Si} \mathrm{Kal}$ signal decreases in two steps indicating the existence of $\mathrm{SiC}, \mathrm{SiO}_{2}$ and Pyrex glass along this line. It is interesting that $\mathrm{C}$ is segregated between $\mathrm{SiO}_{2}$ and Pyrex glass.

Figures 12(a)-(c) show the microstructures of SiC/joining layers made of the as-is $\mathrm{SiC}$ plate observed by using the FE-SEM. As observed in the optical microscope, large pores are not visible in the whole interlayer (a), however, some micron-size pores exist in the interlayer as shown in Figure 12(b), which also indicate that the interlayer is composed of black and white two phases. At the W/interlayer interface shown in Figure 12(c), the interfacial debonding is not observed as opposed to that in Figure 9(d). Figure 13(a) and Figure 13(b) demonstrate the EDX elemental analysis results at points 3 and 4, respectively, in Figure 12(b). The intensities of $\mathrm{C}, \mathrm{O}$ and $\mathrm{Si}$ signals at point 3 (white phase) are almost the same as those at point 1 , however, that of $\mathrm{C}$ signal at point 2 (black phase) is much stronger than those of $\mathrm{O}$ and $\mathrm{Si}$. The elemental mapping shown in Figure 14 demonstrates that the white phase mainly composed of $\mathrm{Si}$ and $\mathrm{O}$, and $\mathrm{C}$ are segregated both in the black phase and the SiC/interlayer interface. 


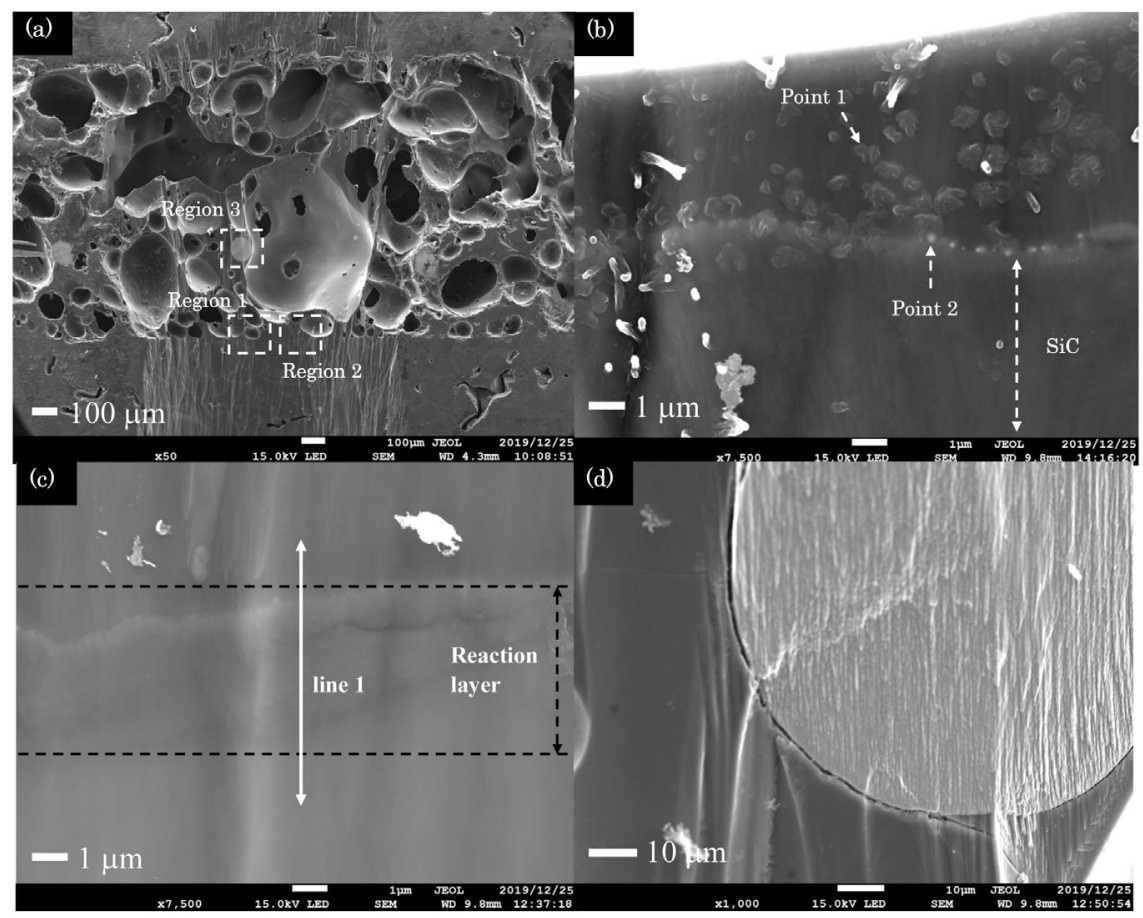

Figure 9. FE-SEM micrographs of the interlayer after joining using the surface-oxidized $\mathrm{SiC}$; (a) joining interface, (b) Region 1 showing the precipitates formation, (c) Region 2 showing the protective oxide layer, (d) Region 3 showing the interlayer around $\mathrm{W}$ wire.
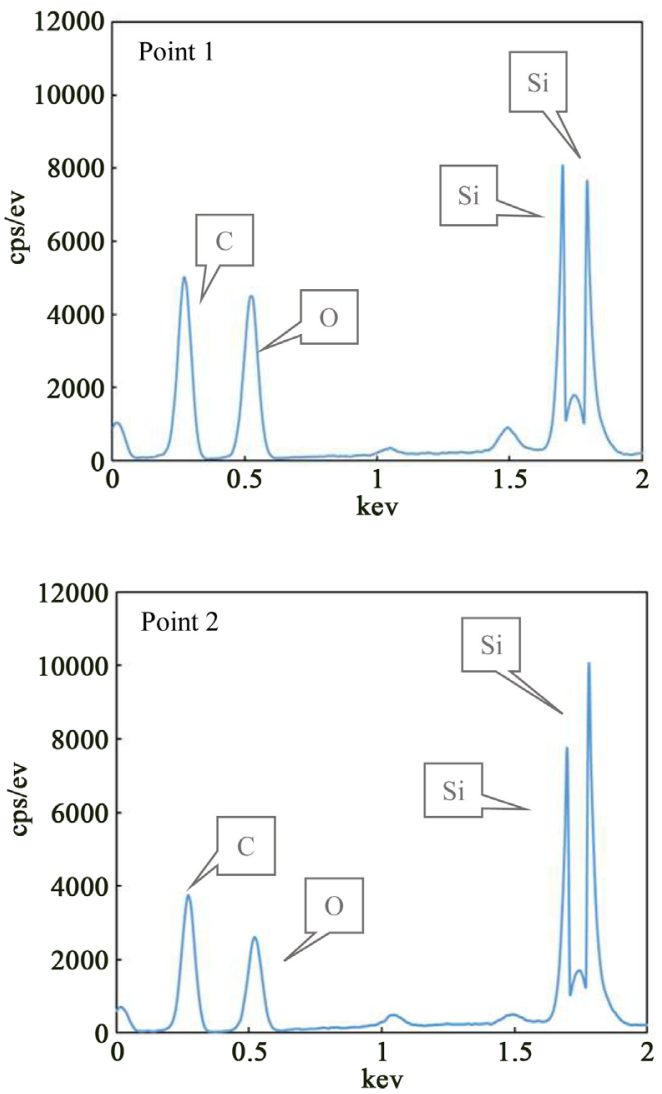

Figure 10. EDX point analyses of point 1 and point 2 shown in Figure 9(b). 


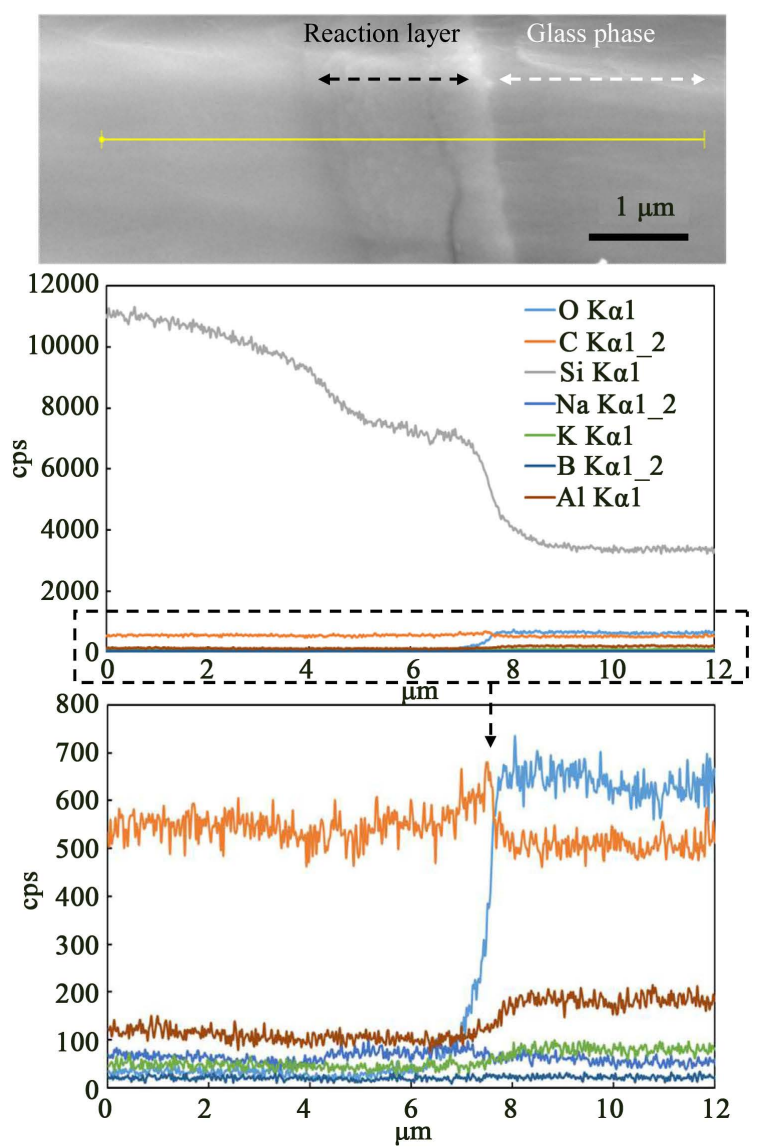

Figure 11. EDX line analysis along the line 1 shown in Figure 14(c).

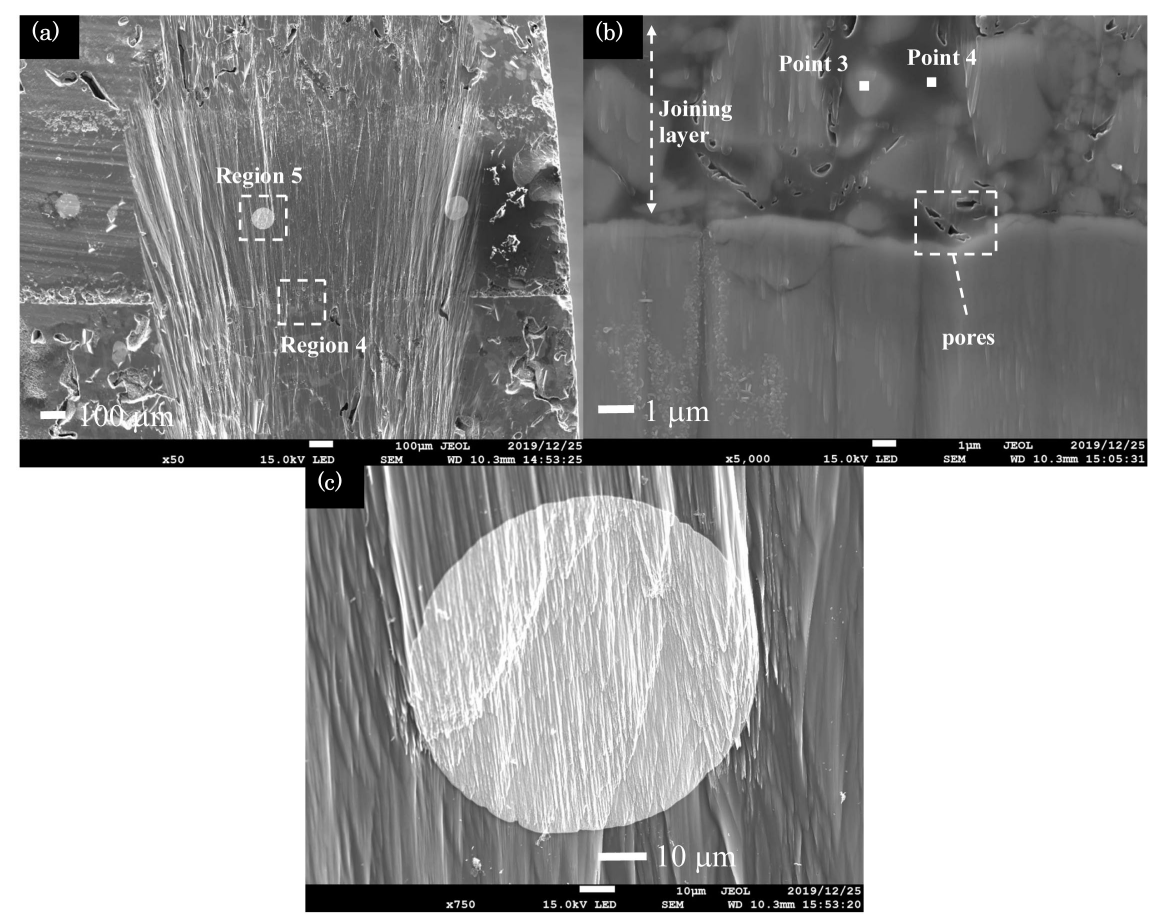

Figure 12. FE-SEM micrographs of the interlayer after joining using the as-is SiC; (a) joining interface, (b) magnified Region 4, (c) magnified Region 5. 

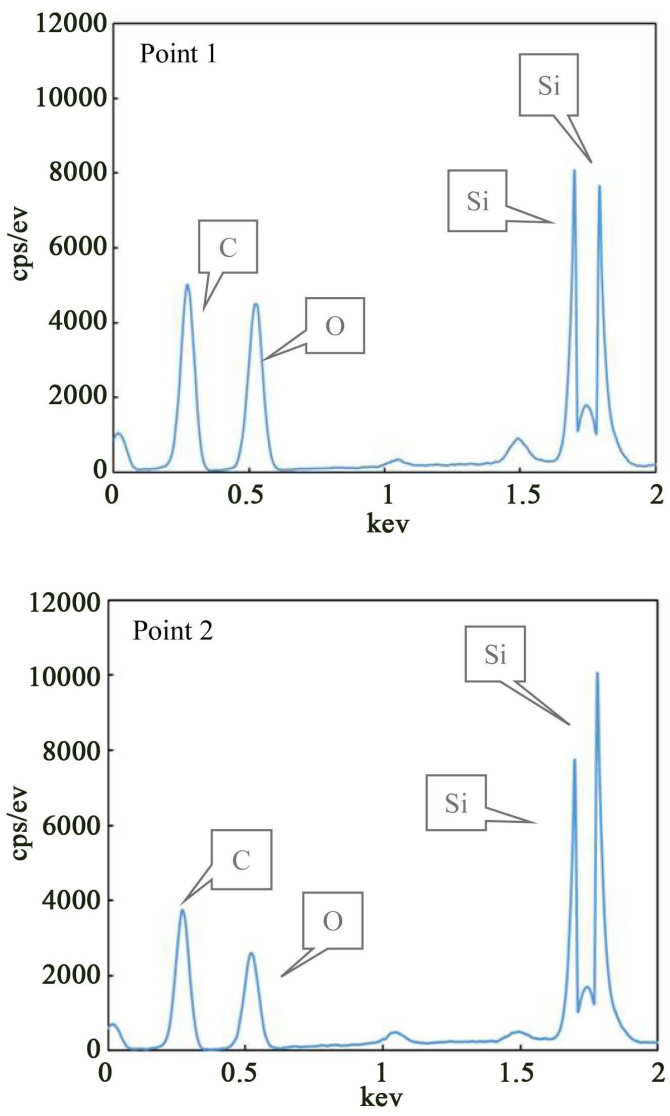

Figure 13. EDX point analysis results of point 3 and point 4 shown in Figure 12(b).

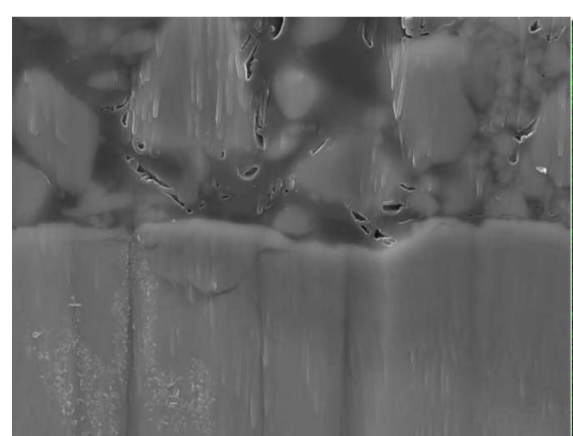

$\mathrm{O}$
C

\section{Si}
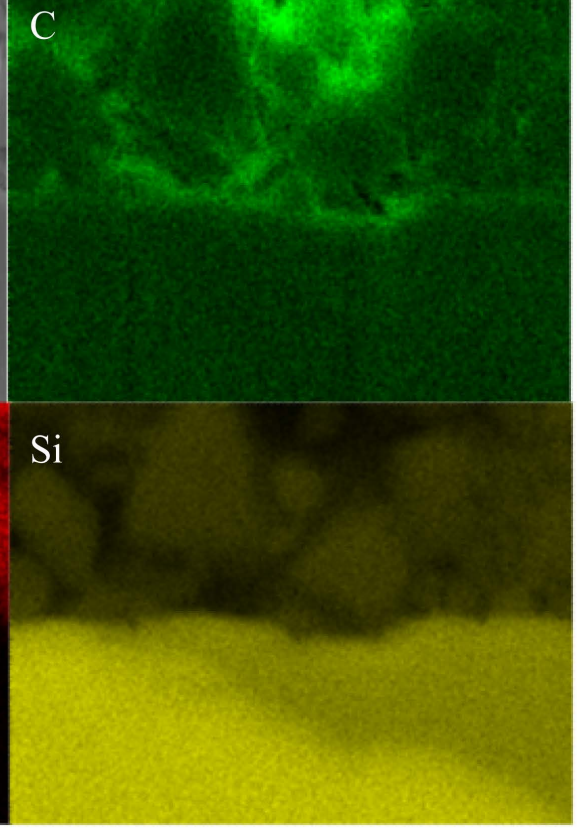

$5 \mu \mathrm{m}$

Figure 14. EDX elemental mapping results. Note that $\mathrm{C}$ segregates in the black phase shown in the SEM micrograph, and that $\mathrm{O}$ and $\mathrm{Si}$ are concentrated in the white phase shown in the SEM micrograph. 


\subsection{Proposed Interfacial Reactions}

Song and Smith [20] proposed a phase diagram for the interaction of oxygen with SiC. In this work, the joining experiments seem to be conducted in the temperature range around $1100^{\circ} \mathrm{C}-1200^{\circ} \mathrm{C}$ by comparing with the results obtained by the wetting experiments. The vacuum level in the vacuum chamber would be around a few $\mathrm{Pa}$, since only an oil-sealed rotary vacuum pump was used for evacuation. According to the phase diagram [20], there are regions 3 and 4 in which the equilibrium reactions represented by Equations (1) and (2), respectively, would proceed considering the current experimental conditions above mentioned.

$$
\begin{gathered}
\mathrm{SiC}(\mathrm{s})+3 / 2 \mathrm{O}_{2}(\mathrm{~g})=\mathrm{SiO}_{2}(\mathrm{~s})+\mathrm{CO}(\mathrm{g}) \\
\mathrm{SiC}(\mathrm{s})+\mathrm{O}_{2}(\mathrm{~g})=\mathrm{SiO}_{2}(\mathrm{~s})+\mathrm{C}(\mathrm{s})
\end{gathered}
$$

When the joining experiment was performed using the surface-oxidized $\mathrm{SiC}$ plates, oxygen diffusion from the chamber atmosphere and/or interlayer to the bulk $\mathrm{SiC}$ would be inhibited by the $\mathrm{SiO}_{2}$ film on the $\mathrm{SiC}$ surface, and oxygen partial pressure would be less than $1.3 \mathrm{~Pa}$ at around $1100^{\circ} \mathrm{C}$, which is namely the region 3. As a result, the reaction (1) proceed to generate $\mathrm{CO}$ gas that resulted in the formation of many large pores, and to precipitate $\mathrm{SiO}_{2}$ and probably the reaction product of $\mathrm{Si}, \mathrm{C}$ and $\mathrm{O}$, namely Silicon Oxicarbide, as demonstrated in Figures 9-11. When the joining experiment was performed using the as-is $\mathrm{SiC}$ plates, the SiC/interlayer assembly would be in equilibrium with the chamber atmosphere in which the oxygen partial pressure would be more than $1.3 \mathrm{~Pa}$ at around $1100^{\circ} \mathrm{C}$, which is namely the region 4 . As a result, the reaction (2) proceed to generate no gas phase, and to precipitate $\mathrm{SiO}_{2}$ and carbon as demonstrated in Figures 12-14.

Cracks were observed between and the interlayer and $\mathrm{W}$ as shown in Figure 9(d), which might be caused due to the excessive volume expansion of $\mathrm{WO}_{3}$ [21]. When the as-is $\mathrm{SiC}$ was used, the carbon precipitate in the interlayer would lower the oxygen activity to prevent the oxidation of $\mathrm{W}$ resulting in no crack formation. In this work, the identification of $\mathrm{W}$ was not investigated in detail, and thus, requires further investigation.

\section{Concluding Remark}

This paper introduced an innovative method for bonding SiC ceramics that would realize the "furnace-free" and "instantaneous" bonding, herein called as the "flash-bonding technique", which was firstly applied for joining $\mathrm{SiC}$ ceramics using the Pyrex glass as an interlayer in this work. It was found that joined bodies made by this technique possessed certain levels of strength high enough for machining.

Since the oxidation of $\mathrm{SiC}$ during bonding is expected by the oxygen supplied from the atmosphere and/or joining material, a protective oxide film was formed on the $\mathrm{SiC}$ surface. The as-is and surface-oxidized $\mathrm{SiC}$ was used for joining expe- 
riments. However, many pores were confirmed in the joining layer of surfaceoxidized SiC joint body, and almost no pore was observed in the joining layer of as-is $\mathrm{SiC}$. The mechanisms for understanding this phenomenon were discussed based on the phase diagram for the interaction of oxygen with $\mathrm{SiC}$ reported in the previous work, which agreed well with the observations using optical and electron microscopy in this work.

As the next step of the "Flash-bonding" technique, bonding large-sized SiC brocks to fabricate joined specimens for the flexural strength tests are anticipated, and further investigation for optimizing the interlayer compositions and bonding conditions would be necessary in the future.

\section{Acknowledgements}

The original concept of the "Flash-bonding" was proposed by Dr. A. M. Glaeser, Professor Emeritus of University of California, Berkeley. We thank his giving helpful suggestions for conducting this research. We also thank the cooperation of the Electronics Research Laboratory, Fukuoka Institute of Technology.

\section{Conflicts of Interest}

The authors declare no conflicts of interest regarding the publication of this paper.

\section{References}

[1] Kunugi, M. (1979) Characteristic of Ceramics. Journal of the Society of Materials Science, Japan, 28, 683-688. https://doi.org/10.2472/jsms.28.683

[2] Yanagida, H. and Takada, M. (1979) Functional Ceramic Materials. The Japan Society for Precision Engineering, 45, 221-227. https://doi.org/10.2493/jjspe1933.45.221

[3] Shinohe, T. (2004) SiC Power Devices. TOSHIBA Review, 59, 49-53.

[4] Itoh, Y. and Suyama, S. (2007) High-Strength Reaction-Sintered Silicon Carbide for Energy and Space Applications. Journal of the Ceramic Society of Japan, 42, 443-446.

[5] Yui, Y., Kimura, T., and Tange, Y. (2017) Development of Reaction-Sintered SiC Mirror for Space-Borne Optics. Proceedings of 2004 International Conference on Space Optics, 10568, 105681E. https://doi.org/10.1117/12.2307958

[6] Soumiya, S. and Inomata, Y. (1988) Silicon Carbide Ceramics. Uchida Rokakuho Publishing Co., Ltd., Tokyo.

[7] Itoh, Y. and Suyama, S. (2006) Development of Applications for High-Strength Reaction-Sintered Silicon Carbide. TOSHIBA Review, 61, 72-75.

[8] Hotta, M. (2015) Joining Techniques of Ceramics. Journal of the Ceramic Society of Japan, 50, 474-478.

[9] Song, S., Gao, Z., Lu, B.,Bao, C., Zheng, B. and Wang, L. (2020) Performance Optimization of Complicated Structural SiC/Si Composite Ceramics Prepared by Selective Laser Sintering. Ceramics International, 46, 568-575. https://doi.org/10.1016/j.ceramint.2019.09.004

[10] Tanaka, H. (2007) Silicon Carbide Sintered Materials. Journal of the Ceramic So- 
ciety of Japan, 42, 342-359.

[11] Ando, M. (2013) Large Scale Pressureless Sintering Silicon Carbide Ceramics. Journal of the Ceramic Society of Japan, 48, 601-605.

[12] Song, S., Lu, B., Gao, Z., Bao, C. and Ma, Y (2019) Microstructural Development and Factors Affecting the Performance of a Reaction-Bonded Silicon Carbide Composite. Ceramics International, 45, 17987-17995. https://doi.org/10.1016/j.ceramint.2019.06.017

[13] Fleisher, A., Zolotaryov, A., Kovalevsky, G., Muller-Kamskii, E., Eshed, M. and Kazakin, V.V. (2019) Reaction Bonding of Silicon Carbides by Binder Jet 3D-Printing, Phenolic Resin Binder Impregnation and Capillary Liquid Silicon Infiltration. $\mathrm{Ce}$ ramics International, 45, 18023-18029. https://doi.org/10.1016/j.ceramint.2019.06.021

[14] Iwamoto, S. and Suga, T. (1990) Ceramics Joining Engineering. The Nikkan Kogyo Shimbun, Ltd., Tokyo.

[15] Cockeram, B.V. (2005) Flexural Strength and Shear Strength of Silicon Carbide to Silicon Carbide Joints Fabricated by a Molybdenum Diffusion Bonding Technique. Journal of the American Ceramic Society, 88, 1892-1899. https://doi.org/10.1111/j.1551-2916.2005.00381.x

[16] Suyama, S. (2013) Development of Joining Technology for SiC Ceramics. Journal of the Ceramic Society of Japan, 48, 610-614.

[17] Saida, K. (2011) Principle of Material Joining and Joining Technology for Metals. The Japan Society for Precision Engineering, 77, 273-277. https://doi.org/10.2493/jjspe.77.273

[18] Goto, T. and Katsui, H. (2013) Oxidation of SiC-Based Ceramics at High Temperature. Materia Japan, 52, 434-439. https://doi.org/10.2320/materia.52.434

[19] Wada, M. (1999) Handbook of Glass Engineering. Asakura Publishing Co., Ltd., Tokyo, 16-21.

[20] Song, Y. and Smith, F.W. (2002) Phase Diagram for the Interaction of Oxygen with SiC. Applied Physics Letters, 81, 3061-3063. https://doi.org/10.1063/1.1514397

[21] Ikeda, Y. (1968) Mechanisms on Glass to Metal Bonding (II). Journal of the Society of Materials Science, Japan, 17, 979-989. https://doi.org/10.2472/jsms.17.979 